\title{
Basis for the development of Quality Control Plans for Arch Bridges
}

\author{
João Amado ${ }^{1}$, Rade Hajdin ${ }^{2}$ \\ DOI: https://doi.org/10.5592/CO/BSHM2017.3.6
}

${ }^{1}$ Infraestruturas de Portugal, Dir. Asset Management, R. de Sta. Apolónia, 65, Lisboa, 1100-468, Portugal

${ }^{2}$ University of Belgrade, Faculty of Civil Engineering, B. kralja Aleksandra, 73, Belgrade, 11000, Serbia

E-mails: ${ }^{1}$ joao.amado@infraestruturasdeportugal.pt; ${ }^{2}$ rade.hajdin@grf.bg.ac.rs.

\begin{abstract}
This work contributes to the systematization of arch bridges specificities, required by a framework to develop Quality Control Plans. The objective of the WG3 of the Cost Action TU1406 is to provide a methodology with detailed step-by-step explanations for establishment of QC plans for different types of bridges, based on the results of WG1 and WG2 as well as on survey of existing approaches in practice. The main concepts presented are therefore those elaborated in the published report of the WG1 of this Cost Action, the developments already made within the scope of WG3, and a literature survey regarding this specific type of bridges. The main challenge of a QC plan is the necessity to connect general data about each bridge, observation findings and other performance indicators with a set of key performance indicators that can be directly related to performance goals, fulfillment of which ensure sufficient quality. A general approach for QC plans was already developed in the scope of WG3 for all types of structures, and is now being analyzed within the scope of arch bridges.
\end{abstract} process

Keywords: arch bridges, quality control plans, performance indicators, performance goals, damage

\section{Introduction}

Efficient bridge management may ultimately be understood to promote the well-being of general public, both in economical and societal sense, and coping at the same time with environmental and sustainable challenges.

Although bridge management systems are widely spread, at different sophistication levels that may include lifecycle analysis, prediction models and optimization algorithms, Quality Control (QC) Plans varies greatly from country to country and sometimes within the same country.

This Cost Action aims to contribute to the development of a guideline for the establishment of QC plans for roadway bridges, in order to reduce the disparity of bridge management quality, through the standardization of the condition assessment and maintenance strategies.

Quality control plans usually rely on the gathering of a set of Performance Indicators (PI), from observations, measurements or other data such as bridge type or year of construction. These PIs are used to obtain Key Performance Indicators (KPI), such as safety, availability or maintainability, among others. In turn, KPIs are compared to Performance Goals (PG), which if fulfilled ensure the sufficient quality of service for a given bridge. How these PIs correlate with each other's and how are KPIs derived from PIs, are the main challenges for the practical implementation of this effort.

While the survey of the established practices among the Cost countries was the objective of the WG1, WG2 address the challenge related with the establishment of performance goals and therefore the KPIs at different levels, namely for the network, for the system (bridge) and for the component. Correlation between this variables and thresholds for performance goals will be analyzed in WG3, through a common framework for different types of structural systems.

\section{Common Framework for the Development of Quality Control Plans}

A common framework for the development of QC plans for different types of structural systems was proposed in the Cost TU1406 workshop held in Delft in October 2016.

As summarized in Figure 1 this framework presents relationships between the entities considered fundamental for bridge management throughout lifecycle (Hajdin, forthcoming). 


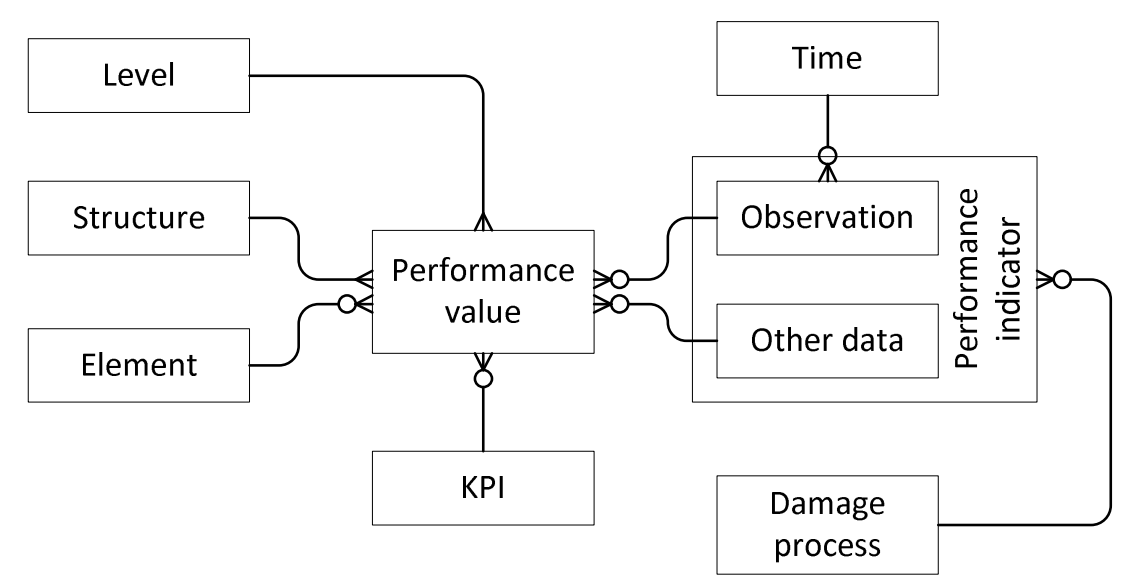

Fig. 1. Common framework for the development of QC plans (adapted from Hajdin, forthcoming)

According to the diagram the entity referred as Structure encompasses different structural systems. Each structure type may include different Elements (deck, columns, beams, etc.) which, in turn, can have attributes such as material properties or construction type.

During its service life, a bridge can experience investigations that may reveal findings and measurements, represented together as entity Observations. Time is therefore an attribute of these observations that might be unique or periodical during the service life of a structure.

Construction year or material properties are examples of data to include in the entity represented in the diagram as Other Data. This data, when related with the Observations, might indicate the existence of a particular Damage Process whose evolution can be tracked, both in a qualitatively or quantitatively manner, by the means of a Performance Indicator.

For each of the considered Performance Indicators, which is as explained above related to Observations and Other Data in a specific moment in Time and in case of forecast to a Damage Process, a Performance Value can be determined. Time, and therefore Performance Values, can be related to past and present events, as well as future predictions according to degradation models for damage processes.

Finally, determined performance values are used to derive Key Performance Indicators, which are directly used to be compared with Performance Goals, thus mirroring management goals and quality requirements. According to the considered time-frame, structure improvement, rehabilitation or maintenance can be planned both for short or long-term, or even demolition in case of structure obsolescence.

\section{Quality Control Plans for Arch Bridges}

Arch bridges represent a significant percentage in most European countries national inventories, with special emphasis on masonry structures. It is important to be aware that many of them are centenarian and the oldest structure type of the bridge population (UIC, 2011). For this reason, there is a significant degradation of the properties of their materials, due to inherent wear and tear over time. In addition, some of this these bridges may be subject to higher loads than those that were anticipated at the time of construction. These circumstances justify the relevance that should be given to the optimization of the maintenance strategies of arch bridges (Aníbal Costa et al., forthcoming).

The selection of the best maintenance strategies for arch bridges requires a good knowledge of the structural behavior, material properties, as well as a correct interpretation and evaluation of the revealed defects and general findings. Structural behavior depends on the geometric and mechanical characteristics of the materials, the structural elements and their related connections, as well as the size of the structures and their environmental exposure (Aníbal Costa et al., forthcoming).

\subsection{Element}

Distinguished proposals regarding arch bridges taxonomy can be found in literature, in most cases related with the main material in use. Seeking a systematic approach for all arch bridges a classification system for arch bridge was recently proposed (Han, Sim \& Kim, 2016). This work, exemplified in Table 1, defined nine different categories, including the material, number of span, road position, support condition, rib shape, rib alignment, stiffening girder type, spandrel type and arch type. 

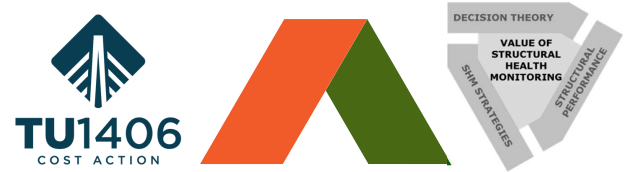

Table 1. Classification code system for arch bridge (adapted from Han, Sim \& Kim, 2016).

Sort/
Material

This taxonomy mirror the complexity of this structural type of bridges for the three most common structural materials. However, some improvements can be made, such as a narrower differentiation of arch types. For instance, in case of masonry structures, three common arch types can be added to this taxonomy, namely: semicircular arch, segmental arch and three centered arch.

\subsection{Time}

In the scope of a bridge quality control plan the Time factor is related with the loadings or events affecting the structure during its service life, as well as to the evolution of deterioration processes acting upon structure. The understanding of the degradation phenomena also allows predicting its evolution. Therefore, Time is related to forecasts.

The survey performed by WG1 of the Cost Action TU1406 and published in the Technical Report (Strauss and Ivanković, 2016) documented a common understanding on investigation workflow to assess bridge condition. This report clearly identified detailed inspections as the basis of any assessment, sub-dived in four time-related categories, namely: visual inspections, e.g. yearly basis; simple checks, for instance 3 years after every main inspection; in-depth examinations or main inspections, for instance every 6 years; special inspections, following exceptional occurrences or incidents. In respect to monitoring techniques the report emphasizes that under no circumstance this actions can replace detailed structural inspection, as they should be always complementary to inspections, adding additional information.

\subsection{Observations and Other Data}

Data that might interest during bridge service life should be recorded in the bridge inventory. General information such as construction year, designer, contractor, scope of rehabilitations, etc., are important features that can be correlated with performance.

Concerning observations taken in the periodic inspections, Bień and Gładysz-Bień (2016) proposed six basic types of defects that can affect arch bridges:

- Deformations: changes of the structure geometry, incompatible with the project, with changes of mutual distances of structure points;

- Material destruction: deterioration of physical and/or chemical features of structural material with relation to designed values;

- Material losses: decrease of designed amount of structural material;

- Material discontinuity: inconsistent with a project discontinuity of a structure material; 
- Contaminations: appearance of any type of an organic or inorganic dirtiness or non-designed plant or other organisms existing on the structure;

- Position changes: dislocation of a structure or its part incompatible with the project, also restrictions in designed displacement capabilities.

References to design values underlying original project can be understood as the as-build condition, with special attention to centenarian bridges where a formal project design may never have existed.

\subsubsection{Performance Indicators}

Based on the survey conducted by WG1 of Cost Action TU1406, regarding bridge inspection and evaluation documents, eleven clusters of performance indicators were identified, related to: defects; material properties, loads, environment, cost and importance, rating, dynamic behavior, original construction and design, bearing capacity, structural integrity and joints, equipment and protection, geometry changes.

Specifically related to masonry arch bridges an analysis to the WG1 database was already accomplished, according to Matos et. al. (2016), linking damages or defects with performance indicators such as structural safety (ULS), serviceability (SLS) and durability (D). According to the results presented in the aforementioned work and shown in Table 2, most common damages can be related with all three referred performance indicators. In addition, the main processes of identification and evaluation for each damage are also presented in the same table.

Table 2. Performance indicators for masonry arch bridges (Matos et. al., 2016).

\begin{tabular}{|c|c|c|c|c|c|}
\hline \multirow{3}{*}{ Damage characteristic } & \multicolumn{5}{|c|}{ Performance Indicator } \\
\hline & \multirow{2}{*}{ Detection } & \multirow{2}{*}{ Evaluation } & \multicolumn{3}{|c|}{ Level } \\
\hline & & & $\mathrm{D}$ & SLS & ULS \\
\hline Joints deficiency & VI & $\mathrm{DC}$ & $\mathrm{X}$ & $\mathrm{X}$ & $\mathrm{X}$ \\
\hline Joints leaking & VI & $\mathrm{DC}$ & $\mathrm{X}$ & $\mathrm{X}$ & $\mathrm{X}$ \\
\hline Dewatering deficiency & VI & $\mathrm{DC}$ & $\mathrm{X}$ & $\mathrm{X}$ & $\mathrm{X}$ \\
\hline Contamination & VI & I & $\mathrm{X}$ & $X$ & $\mathrm{X}$ \\
\hline Cracks & $\mathrm{DM}$ & $\mathrm{DC}$ & $\mathrm{X}$ & $\mathrm{X}$ & $\mathrm{X}$ \\
\hline Spalling & VI & $\mathrm{DC}$ & $\mathrm{X}$ & $\mathrm{X}$ & $\mathrm{X}$ \\
\hline Deformation & VI & DC & $\mathrm{X}$ & $\mathrm{X}$ & $\mathrm{X}$ \\
\hline Displacement & DM & I & $X$ & $\mathrm{X}$ & $\mathrm{X}$ \\
\hline Loose of stones/bricks & VI & DC & $\mathrm{X}$ & $\mathrm{X}$ & $X$ \\
\hline
\end{tabular}

$\mathrm{DM}$ - direct measurement; VI - visual inspection; DC - damage catalogue; I - inspection

Future work will include a review of Performance Indicators form WG1 database, regarding all types of arch bridges. With this systematization performance thresholds or criteria can be searched, in order to assist decision making regarding choices such as maintenance actions, tests, monitoring or others.

\subsection{Damage Process}

The existence of damages can be related with two different types of processes, as proposed by Hajdin (2016): the interceptable (observable) processes and non-interceptable processes (accidents, earthquakes, etc.).

Interceptable (observable) processes in masonry arch bridges, as proposed by UIC (2006), were categorized accordingly their relation with demand or damaging processes (Amado, forthcoming).

More generally for the three most common structural material of arch bridges, masonry, steel and concrete, Bień and Gładysz-Bień (2016) proposed, as shown in Table 4, three main groups of the degradation mechanisms: physical, chemical and biological.

The purpose of indicating thresholds or goals for performance indicators requires a deep understanding of the phenomenon affecting bridges, their causes, consequences, actual degree or extend and possible progression. Therefore, the calculation of a certain performance value always depends on the consideration of certain observations and other relevant data, correlated with the knowledge of the damaging processes affecting bridges. 

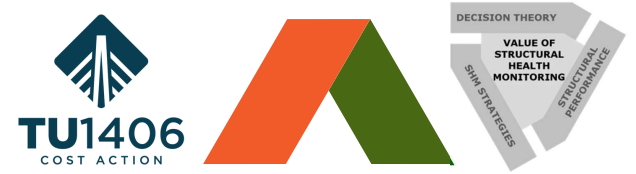

In other words, diagram entity Damage Process is primarily related with Observations or Other Data, and not directly connected to Performance Values or KPIs.

Table 3. Degradation mechanisms according to material of arch bridge (adapted from Bień \& Gładysz-Bień, 2016)

\begin{tabular}{|c|c|c|c|c|}
\hline & \multirow{2}{*}{ Degradation mechanisms } & \multicolumn{3}{|c|}{ Material of arch bridge } \\
\hline & & concrete & steel & masonry \\
\hline \multirow{10}{*}{ 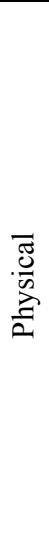 } & Accumulation of inorganic contamination & $\bullet$ & $\bullet$ & $\bullet$ \\
\hline & Freeze/thaw actions & $\bullet$ & ○ & $\bullet$ \\
\hline & Erosion & $\bullet$ & ○ & $\bullet$ \\
\hline & Crystallization & $\bullet$ & $\mathrm{X}$ & $\circ$ \\
\hline & Extremal temperature influence & ० & • & ○ \\
\hline & Rheological processes & $\bullet$ & ○ & $\circ$ \\
\hline & Overloading & $\bullet$ & • & $\bullet$ \\
\hline & Leaching & $\bullet$ & $\mathrm{X}$ & $\bullet$ \\
\hline & Fatigue & ० & $\bullet$ & $\circ$ \\
\hline & Changes of geotechnical conditions & $\bullet$ & $\bullet$ & $\bullet$ \\
\hline \multirow{4}{*}{ 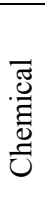 } & Carbonization & $\bullet$ & $\mathrm{X}$ & $\circ$ \\
\hline & Corrosion & $\bullet$ & $\bullet$ & $\mathrm{X}$ \\
\hline & Aggressive environmental impact & $\bullet$ & • & • \\
\hline & Reactions between material components & $\bullet$ & $\circ$ & $\circ$ \\
\hline \multirow{4}{*}{$\begin{array}{l}\overline{0} \\
.00 \\
00 \\
0 \\
0 \\
0\end{array}$} & Accumulation of organic contamination & $\bullet$ & $\bullet$ & $\bullet$ \\
\hline & Influence of microorganisms & $\bullet$ & $\bullet$ & $\bullet$ \\
\hline & Influence of plants & $\bullet$ & $\circ$ & $\bullet$ \\
\hline & Influence of animals & 0 & - & o \\
\hline
\end{tabular}

- - basic mechanism; o - supplementary mechanism; X - not applicable

\subsection{Level}

Consequences of a certain phenomenon can be analyzed at different levels. If in a close look the functionality of a single element is affected, it might have an effect on the whole structure stability and therefore contribute to a certain performance of the network, depending on the bridge importance or redundancy on the network. Three levels were identified and analyzed in WG1 survey, and they should be considered in the establishment of QC plans: component level, system level and network level. However, it is possible to consider that performance goals will not have to be established at all levels, as a correct modeling may mirror the propagation of effects from the element level to the network level.

Obviously, these levels do not depend from the structural type, nevertheless, for arch bridges, heritage concerns might be much more common than for other bridge types, even if not considering landmark bridges. Heritage might therefore be a factor at the network level, whose primary goal to be reached is priority repair ranking among a set of bridges with detected necessities. This ranking should be based on bridge condition assessment, accomplished through standard inspection and evaluation procedures, with additional evaluation of bridge importance in the network (Strauss and Ivanković, ed., 2016).

The structure level is related with bridge functionality as whole, in order to assess the impact of the damaged element to the entire structure. The importance of the bridge element can be evaluated according to the structural safety, serviceability, traffic safety and durability (DIN 1076 1999).

If one considers bridge inspections as the basis of a systematic management, the element level will be the ground level as in general inspections include observations detected on bridge elements. This level comprises damage detection, identification, evaluation (comparing with a certain threshold) and more detailed assessment such as testing, if necessary. 
At the element level it's essential to know, depending on bridge type, that the possible damages and degradation processes, on element level may compromise the whole structure

\subsection{Performance Value}

The Performance Value, as represented in the Fig. 1. diagram, puts together all relevant data that has impact on the performance indicator. On the other hand each KPI has to consider the correlation of the performance values contributing to this KPI. For each Performance Indicator a value will reflect the findings, usually through the use of a rating index.

As stated in WG1 Technical Report, a similar approach is used in several countries, and a five-level rating system is presented as a typical example. In this example, extreme grades represent, respectively, "No or very slight damage" and "Extreme damage". Middle grades are summarized as "Slight damage", "Moderate to severe damage" and "Severe damage".

\subsection{Key Performance Indicators}

The main idea of the Cost Action TU1406 is to provide a set of standardized tools to support the establishment of QC plans for roadway bridges. These tools are considered to be performance indicators and performance goals, which may differ for each type of bridges. The survey performed in the scope of WG1 revealed, after additional clustering and homogenization, that the most widely used performance indicator is obtained by visual inspections, despite the name vary from condition index, conditions rating, and deterioration index, among others (Strauss and Ivanković, ed., 2016).

Cleary, while some countries rely on this indicator to perform their management activities others have started to consider other relevant indicators, seeking to express concepts such as remaining service life, safety indexreliability, vulnerability or robustness. These terms, or others that can be defined, are always dependent of observations and related with other bridge data, previously also defined as performance indicators. Therefore, these top-level definitions are usually considered as Key Performance Indicators (KPIs). Finally, in a QC plan these KPIs are directly used to be compared to Performance Goals. The PG can be extremizing goals meaning that the corresponding KPI has to be maximized or minimized, or satisfying goals represented as thresholds.

The establishment of QC plans, seeks to identify crucial KPIs, based on most relevant performance indicators for arch bridges that might, or not, be common for bridges in general.

\section{Future Developments}

A review of the WG1 Technical Report is underway in order to identify most important performance indicators for arch bridges. From WG2 is expected the identification of KPI's that can easily be adopted by roadway agencies in different countries. Subsequent action will be to model the impact of different combinations of structure types and elements, observations and other relevant data with KPI's.

\section{References}

Rade Hajdin. From performance indicators to performance goals. In Proceedings of the WG2 and WG3 Workshop, Bridge performance goals and quality control plans, COST Action TU 1406, E-book, forthcoming.

UIC. Recommendations for the inspection, assessment and maintenance of masonry arch bridges, 2nd edition, Code 778-32011, International Union of Railways - UIC, 2011.

Aníbal Costa, Hugo Perneta, Cristina Costa, António Arêde, Humberto Varum, Guide for the Assessment of Masonry Bridges. Infraestruturas de Portugal, forthcoming.

Alfred Strauss, A. Mandić Ivanković, editors. Performance Indicators for Roadway Bridges of Cost Action TU1406. WG1 Technical Report, Cost Action TU1406, 2016.

Bień and Gładysz-Bień. Gerontology of Arch Bridges. In Proceedings of the 8th International Conference on Arch Bridges, pages 1269-1278, Wrocław, Wrocław, Poland, 2016.

José Matos, Alfred Strauss, Hugo Guimarães, and Ivan Zambon. Overview of Performance Indicators for Arch Bridges in Europe, In Proceedings of the 8th International Conference on Arch Bridges, Wrocław, Poland, 2016.

Rade Hajdin. Report from WG3: Establishment of Quality Control Plans. In Proceedings of the 2nd Workshop Meeting, An overview of Key Performance Indicators across Europe and Overseas, pages 653-671, Faculty of Civil Engineering, University of Belgrade, Serbia, 2016. 
João Amado. Interceptable Decaying Processes in Arch Bridges. In Proceedings of the WG2 and WG3 Workshop, Bridge performance goals and quality control plans, COST Action TU 1406, E-book, forthcoming.

DIN 1076 - Ingenieurbauwerke im Zuge von Straßen und Wegen; Überwachung und Prüfung, Ausgabe 11/1999 